Review

\title{
Is High Dose Therapy Superior to Conventional Dose Therapy as Initial Treatment for Relapsed Germ Cell Tumors? The TIGER Trial
}

\author{
Darren R. Feldman'1 , Robert Huddart², Emma Hall ${ }^{3}$, Jörg Beyer ${ }^{4}$, Thomas Powles ${ }^{\natural} \bowtie$ \\ 1. Genitourinary Oncology Service, Memorial Sloan-Kettering Cancer Center, New York USA \\ 2. Division of Radiotherapy and Imaging, Institute of Cancer Research (ICR), Royal Marsden Hospital, London UK \\ 3. Institute of Cancer Research, Clinical Trials and Statistics Unit (ICR-CTSU), London, UK \\ 4. Director of Oncology, Vivantes Krankenhaus Am Urban, Berlin, Germany \\ 5. Barts Cancer Institute, Queen Mary University of London, London
}

$\bowtie$ Corresponding author: Dr. Thomas Powles. thomas.powles@bartsandthelondon.nhs.uk

( ) Ivyspring International Publisher. This is an open-access article distributed under the terms of the Creative Commons License (http://creativecommons.org/ licenses/by-nc-nd/3.0/). Reproduction is permitted for personal, noncommercial use, provided that the article is in whole, unmodified, and properly cited.

Received: 2011.05.14; Accepted: 2011.06.15; Published: 2011.07.01

\begin{abstract}
Metastatic germ cell tumours (GCTs) are usually cured with cisplatin based chemotherapy and standard treatment algorithms are established. However when this treatment fails and the disease relapses, standard treatment is much more uncertain. Both conventional dose therapy (CDT) and high dose therapy (HDT) are widely used, due to the lack of conclusive data supporting one specific approach. A recent retrospective analysis focusing on this population suggested a significant benefit for HDT. Retrospective analyses are prone to bias, and therefore while this data is provocative it is by no mean conclusive. For this reason the international community is supporting a prospective randomised trial in this area comparing CDT(TIP) with sequential HDT (TICE). The planned open labelled randomised phase III study (TIGER) is due to open in 2011 and will recruit 390 patients to detect a 13\% difference in 2 year progression free survival (primary endpoint). It is hoped that this large study will conclusively resolve the uncertainty which currently exists.
\end{abstract}

Key words: Metastatic germ cell tumours, dose therapy, relapses

\section{Background}

Testicular cancers or germ cell tumours (GCT) represent the most common malignancy affecting adolescent and young adult men in Europe and the United States. The peak incidence at approximately $17 / 100,000$ occurs in the $25-34$ age group. Therefore GCTs account for the greatest average number of years of life lost of any adolescent or adult malignancy [1].

The majority of patients with metastatic GCT are cured with initial chemotherapy. This treatment is well defined and usually consists of cisplatin based therapy. However, if the disease relapses, outcomes are much less secure and despite further chemotherapy, the majority of patients die from GCT $[2,3]$.
Conventional-dose chemotherapy (CDCT) and high-dose chemotherapy (HDCT) are both used as salvage treatment strategies for patients with metastatic GCTs who experience progression with or after first-line treatment $[3,4]$. At recent international consensus meetings (G3 testis meeting: ASCO 2010) investigators agreed that identifying the optimal initial salvage approach (CDT vs HDT) is the most pressing question remaining in GCTs.

\section{Evidence for CDCT at relapse}

A number of CDCT regimens based on ifosfamide \& cisplatin plus vinblastine (VeIP), etoposide (IPE or VIP) or paclitaxel (TIP) have been used 
over the last 2 decades [3,5]. When considering all relapsed or refractory patients, complete response (CR) rates of around $50-60 \%$ and 2 year PFS of $20-35 \%$ have been seen [3]. TIP has arguably become the most widely accepted CDT regimen over the last 5 years. It consists of 4 cycles of paclitaxel ifosfamide and cisplatin therapy given in 3 weekly intervals with G-CSF support. Single arm phase II data supports its use is this setting with 2 year PFS figures of approximately $30 \%$ [5].

\section{Evidence for HDCT at relapse}

GCTs are an ideal model for the study of intensive HDCT. This is because it is associated with a high response rate to chemotherapy, bone marrow involvement is extremely rare, patients are young and tolerate intensive therapy well, the dose-limiting toxicity of known active agents is myelosuppression and a dose response relationship has been suggested for two such agents (carboplatin and etoposide) [4] Investigators have therefore used HDCT in an attempt to improve outcomes in this setting.

The most robust single institution data comes from Indiana University: 184 consecutive metastatic testicular cancer patients were treated with 2 cycles $(n=173)$ or 1 cycle $(n=11)$ of high-dose etoposide \& carboplatin [6]. During a median follow-up of 48 months, $63 \%$ of patients achieved a durable remission and 5 year OS was approximately $65 \% 11$. This trial excluded some unfavorable groups of patients such as those with extragonadal primary tumor sites and late relapses.

The TI-CE high-dose regimen was developed more recently with the goal of targeting patients with an unfavourable prognosis with CDT [7]. TI-CE consists of an initial 2 cycles of rapidly recycled paclitaxel and ifosfamide followed by stem cell collection. The high dose component of this therapy consists of 3 cycles of carboplatin and etoposide, each supported with stem cell infusion (figure 1). In a phase II study consisting of 107 patients, complete response rates were high and the 5 year disease free survival was $47 \%$ with an overall survival of $52 \%$. The regimen has good stem cell mobilisation rates $(7 / 107$ patients failed to receive any HDCT compared with 13/108 in previous studies with other regimens [2].

\section{Retrospective prognostic factor analysis}

To test the benefit of HDT in comparison CDT 2 retrospective comparisons have been made. In 2002, Beyer et al conducted a retrospective analysis on 55 matched pairs of pts receiving HDT or CDT [8]. Hazard ratios (HR) favouring HDCT of between $0.72 \&$ 0.84 for event free survival \& between $0.77 \& 0.83$ for
OS (depending on the type of analysis) were reported Recently the International Prognostic Factors Study Group have reported retrospective data on 1,594 patients with GCTs treated in the initial salvage setting $[9,10]$. All patients had experienced progression after at least 3 and no more than 6 cisplatin-based chemotherapy cycles. These patients were treated with either cisplatin-based CDT $(n=773)$ or carboplatin-based HDT $(n=821)$. Data was collected from 38 centres worldwide. In this non-randomised comparison, the HR for PFS was 0.44 (95\% CI, 0.39 to 0.51 ) stratified by prognostic category, and for OS was 0.65 (95\% CI, 0.56 to 0.75), favouring HDT. Results were consistent within each prognostic category except among low-risk patients, for whom similar overall survival was observed between the two.

\section{Prospective Randomised Trials in Relapsed disease}

Any potential benefit of HDT over CDT should be confirmed in a randomized trial. Only one such trial has been undertaken organised by European investigators led by French GCT group (GETUG) and the European Bone Marrow transplant (NCT00002566) [11]. This study randomised 280 GCT patients who had progressed after first-line chemotherapy to 4 cycles of CDCT or 3 cycles of the same regimen followed by a single cycle of HDCT (carboplatin, etoposide, \& cyclophosphamide), followed by autologous bone marrow and/or peripheral blood stem cell transplantation. With 45 months median follow-up, no statistically significant differences were seen in terms of event-free survival or overall survival. There were criticisms of the trial methodology: only 98/140 patients randomised to HDCT actually received it and there was a higher than expected rate of treatment mortality ( $3 \%$ for CDT $v 7 \%$ for HDT). Finally a single cycle rather than sequential cycles of HDCT were given. Therefore many believe that the trial did not definitively settle the HDCT vs. CDCT question resulting in widespread use of HCT.

\section{Lack of consensus on the treatment of re- lapsed GCTs?}

The conflict between retrospective and randomised data has led to significant heterogeneity of initial salvage treatment approaches on the local, regional and national levels. The recent retrospective analysis of 1594 patients with relapsed disease demonstrated the international uncertainty about the optimal initial salvage treatment approach, with $52 \%$ being treated with CDT and $48 \%$ receiving HDT [10]. Therefore when this data was presented at ASCO 2010, the international GCT community met and decided a pro- 
spective study comparing CDT and HDT was the most presenting question in GCTs. The TIGER (RANDOMIZED PHASE III TRIAL OF INITIAL SALVAGE CHEMOTHERAPY FOR PATIENTS WITH GERM CELL TUMORS) trial (PI: Darren Feldman [MSKCC]; Co-PI: Robert Huddart [Royal Marsden] and Thomas Powles (Barts cancer Institute) has been specifically designed to address this issue in a prospective manner using the most recent and relevant chemotherapy regimens (TIP and TI-CE). The trial will be an international collaboration among many centres across North America (United States and Canada), Europe (UK, Germany, France, Italy, Spain, Denmark) and Australia.

\begin{tabular}{|c|c|c|c|}
\hline \multirow[b]{2}{*}{$\begin{array}{l}\text { Eligibility } \\
\text { - Histologically-confirmed GCT } \\
\text { - PD following } 1^{\text {st }} \text {-line chemo } \\
\text { - Prior treatment included } \geq 3 \text { but } \\
\leq 6 \text { cycles of cisplatin-based } \\
\text { chemo } \\
\text { - Adequate organ function for } \\
\text { HDCT } \\
\text { - Any primary site }\end{array}$} & \multicolumn{2}{|c|}{$P D$ after initial systemic therapy } & \multirow[b]{2}{*}{$\begin{array}{c}\text { Stratification } \\
\text { - IGCCCG-2 risk group } \\
\text { - Country of enrollment }\end{array}$} \\
\hline & $R a$ & $\begin{array}{l}\text { ization } \\
1 \\
\text { 34) }\end{array}$ & \\
\hline \multicolumn{2}{|c|}{$\begin{array}{l}\text { Cycles 1-4 (q21d) } \\
\text { - Paclitaxel } 250 \mathrm{mg} / \mathrm{m} 2 \text { IV over } 24 \text { hrs (d1) } \\
\text { - Ifosfamide 1500mg/m2 IV + mesna } \\
\text { support (d2-5) } \\
\text { - Cisplatin 25mg/m2 IV (d2-5) } \\
\text { - Peg-G-CSF 6mg SQ (d6) or G-CSF } \\
\text { 5mcg/kg (d7-13) }\end{array}$} & \multicolumn{2}{|c|}{$\begin{array}{l}\text { Cycles 1-2 (q14d) } \\
\text { - Paclitaxel } 250 \mathrm{mg} / \mathrm{m}^{2} \mathrm{IV} \text { over } 24 \mathrm{hrs}(\mathrm{d} 1) \\
\text { - Ifosfamide } 2000 \mathrm{mg} / \mathrm{m}^{2} \mathrm{IV}+\text { mesna support } \\
\text { (d2-4) } \\
\text { - G-CSF 10mcg/kg/d (d4-14)* } \\
\text { - Stem cell collection }(d 11-14)^{*} \\
\text { Cycles 3-5 (q21d) } \\
\text { - Carboplatin AUC=8 IV (d1-3) } \\
\text { - Etoposide } 400 \mathrm{mg} / \mathrm{m} 2 \mathrm{IV}(d 1-3) \\
\text { - Stem cell infusion } \\
\text { - G-CSF 10mcg/kg/d (d3-ANCR) or Peg-G- } \\
\text { CSF 6mg SQ once (d5) }\end{array}$} \\
\hline $\begin{array}{l}\text { Primary Endpoint: } \\
\text { Secondary Endpoints: }\end{array}$ & \multicolumn{3}{|c|}{$\begin{array}{l}\text { - Progression-Free Survival (PFS) at } 2 \text { years } \\
\text { - Overall Survival (OS) at } 3 \text { years } \\
\text { - Favorable Response Rate (CR + PR-neg markers) } \\
\text { - Toxicity } \\
\text { - Prospective Evaluation of the IGCCCG-2 Prognostic Mode } \\
\text { - Biologic correlates }\end{array}$} \\
\hline
\end{tabular}

Figure 1. Overview of TIGER study summarizing treatment regimens 


\section{Details of the regimens}

\section{CDCT using the TIP regimen (Control)}

Cycles 1-4 (q21d): Paclitaxel 250mg/m2 IV over $24 \mathrm{hrs}$ (d1), Ifosfamide $1500 \mathrm{mg} / \mathrm{m} 2 \mathrm{IV}+$ mesna support (d2-5), Cisplatin 25mg/m2 IV (d2-5), Peg-G-CSF $6 \mathrm{mg}$ SQ (d6 or $\mathrm{d} 7$ ) or G-CSF $5 \mathrm{mcg} / \mathrm{kg}$ (d7-18 or ANCR).

\section{HDCT using TI-CE}

Cycles 1-2 (q14d): Paclitaxel 250mg/m² IV over $24 \mathrm{hrs}$ (d1), Ifosfamide $2000 \mathrm{mg} / \mathrm{m}^{2}$ IV + mesna support (d2-4), G-CSF $10 \mathrm{mcg} / \mathrm{kg} / \mathrm{d}$ (d4-14), Stem cell collection (d11-14).

Cycles 3-5 (q21d): Carboplatin AUC=8 IV (d1-3), Etoposide $400 \mathrm{mg} / \mathrm{m} 2$ IV (d1-3), Stem cell infusion, G-CSF $10 \mathrm{mcg} / \mathrm{kg} / \mathrm{d}$ (d3-ANCR) or Peg-G-CSF $6 \mathrm{mg}$ SQ once (d5).

\section{Summary of inclusion criteria of TIGER trial}

Men over the age of 16 with confirmed GCT histology will be included in the study. Patients will require unequivocal progression of measurable disease after a minimum of 3 and no more than 6 cisplatin-based chemotherapy cycles, administered as part of first-line (initial) chemotherapy.

\section{Statistical considerations of the TIGER trial}

The primary endpoint is 2 year progression free survival. With 390 patients (248 PFS events) there will be $80 \%$ power to detect a $13 \%$ difference in 2 year PFS assuming the 2 year PFS in the control arm (TIP) is $30 \%$. There will also be $54 \%$ to $71 \%$ power to detect a difference of $12 \%$ in 3 year overall survival, the most important secondary endpoint of the trial. This value will depend on the 3 year overall survival of TIP-treated patients, which is estimated to be $50 \%$ based on the values from the IT94 CDCT arm \& the large retrospective observational study $[5,10]$.

\section{Summary}

The treatment for relapsed GCTs is an area of equipoise. Both CDCT and HDCT are widely used and current data potentially supports both approaches. The GCT community is therefore investigating this issue as part of a randomised phase III study comparing TIP and TI-CE.

\section{Conflict of Interest}

The authors have declared that no conflict of interest exists.

\section{References}

1. [Internet] NIH. Average Years of Life Lost Per Person Dying of Cancer, All Races, Both Sexes, 2004; SEER DATABASE 1975-2004. http://seer.cancer.gov/csr/1975_2004/results_ figure/sect_01_zfig.19.pdf.

2. Lorch A, Kollmannsberger C, Hartmann JT, et al. Single versus sequential high-dose chemotherapy in patients with relapsed or refractory germ cell tumors: a prospective randomized multicenter trial of the German Testicular Cancer Study Group. J Clin Oncol. 2007 Jul 1;25(19):2778-84.

3. Daugaard G. Management of poor-prognosis or relapsed germ-cell cancer. BJU Int. 2009 Nov;104:1392-7.

4. Connolly RM, McCaffrey JA. High-dose chemotherapy plus stem cell transplantation in advanced germ cell cancer: a review. Eur Urol. 2009 Jul;56(1):57-64.

5. Kondagunta GV, Bacik J, Donadio A, Bajorin D, Marion S, Sheinfeld J, Bosl GJ, Motzer RJ. Combination of paclitaxel, ifosfamide, and cisplatin is an effective second-line therapy for patients with relapsed testicular germ cell tumors. J Clin Oncol. 2005 Sep 20;23(27):6549-55.

6. Einhorn LH, Williams SD, Chamness A, Brames MJ, Perkins SM, Abonour R. High-dose chemotherapy and stem-cell rescue for metastatic germ-cell tumors. N Engl J Med. $2007 \mathrm{Jul}$ 26;357(4):340-8.

7. Feldman DR, Sheinfeld J, Bajorin DF, Fischer P, Turkula S, Ishill N, Patil S, Bains M, Reich LM, Bosl GJ, Motzer RJ. TI-CE high-dose chemotherapy for patients with previously treated germ cell tumors: results and prognostic factor analysis. J Clin Oncol. 2010 Apr 1;28(10):1706-13.

8. Beyer J, Stenning S, Gerl A, Fossa S, Siegert W. High-dose versus conventional-dose chemotherapy as first-salvage treatment in patients with non-seminomatous germ-cell tumors: a matched-pair analysis. Ann Oncol. 2002 Apr;13(4):599-605.

9. International Prognostic Factors Study Group, Lorch A, Beyer J, Bascoul-Mollevi C, Kramar A, Einhorn LH, Necchi A, Massard C, De Giorgi U, Fléchon A, Margolin KA, Lotz JP, Germa Lluch JR, Powles T, Kollmannsberger CK. Prognostic factors in patients with metastatic germ cell tumors who experienced treatment failure with cisplatin-based first-line chemotherapy. J Clin Oncol. 2010 Nov 20;28(33):4906-11

10. Lorch A, Bascoul-Mollevi C, Kramar A, Einhorn L, Necchi A, Massard C, De Giorgi U, Fléchon A, Margolin K, Lotz JP, Germà-Lluch JR, Powles T, Kollmannsberger C, Beyer J. Conventional-Dose Versus High-Dose Chemotherapy As First Salvage Treatment in Male Patients With Metastatic Germ Cell Tumors: Evidence From a Large International Database. J Clin Oncol. 2011; 29(16):2178-84.

11. Pico JL, Rosti G, Kramar A, et al. A randomised trial of high-dose chemotherapy in the salvage treatment of patients failing first-line platinum chemotherapy for advanced germ cell tumours. Ann Oncol. 2005 Jul;16(7):1152-9. 